\title{
AUTOMATIC GLUCOSE INSULIN REGULATION SYSTEM- COMPARISON OF EMBEDDED CONTROL DESIGN AND HARR WAVELET METHOD FOR TYPE-1 DIABETES
}

\author{
${ }^{1}$ Arangasamy, R., ${ }^{2}$ J. Sundararajan, ${ }^{3}$ Ila Vennila and ${ }^{4}$ G. Shankar \\ ${ }^{1}$ Department of Electronics and Communication Engineering, Paavai Engineering College, Namakkal, India \\ ${ }^{2}$ Paavai College of Technology, Namakkal, India \\ ${ }^{3}$ Department of Electrical and Electronics Engineering, PSG College of Technology, Coimbatore, India \\ ${ }^{4}$ Department of Physics, Government College of Engineering, Salem, India
}

Received 2013-11-23; Revised 2013-12-11; Accepted 2014-01-11

\begin{abstract}
This article is aimed to inject insulin for type 1 diabetes using pumping the insulin with respect to meal disturbance. We have used the embedded linear parameter varying methodology controller and the final results were compared with the Harr wavelet mathematical values. In this article, there are three things we need to focus. First is the sensor values which is to be monitored from the sensors and next is the lab information. Depending on the patients test details the insulin has to be injected. The comparison of lab details with the Patients current sensor values play a vital role in determining the insulin level for a patient. Finally the feedback has to be obtained with the help of those comparisons and it has to be sent once again as a loop to the controller for later comparison and also for database information. The embedded controller is the key element for updating all the information about the patient and it will control all the parameters of the board. The experimental results shows that the proposed method has much better potential in terms of solution accuracy as $97 \%$ and better convergence speed in comparison with Haar Wavelet Model which proved $89.09 \%$ of accuracy of the assured values of our experiments.
\end{abstract}

Keywords: Blood Glucose, Insulin, Glucose Tolerance Test, Pre-Diabetes, Controller Section, Pumping Method, Haar Wavelet

\section{INTRODUCTION}

The diabetes is the most common widespread disease. Insulin is an enzyme, made by the pancreas which releases insulin into the blood. If our body is not able to produce insulin, then the glucose stays in our blood and makes the blood glucose level high thriving pre-diabetes or diabetes. Blood glucose control is the most rigorous research area. Insulin-dependent diabetes is called Type 1 diabetes (Andras et al., 2009; Bergenstal et al., 2010; Thabit, 2012; Anantha et al., 2013), is the most frequently occurred diabetes to adults. The other diabetes is called Type 2 diabetes which is insulin-independent diabetes (Ismail et al., 2013), our research is concentrated on Type 1 diabetes. The statistics of the World Health Organization (WHO) mention that an increase of adult diabetes population from 171 million people in the year 2000 to 366 million worldwide in the year 2030 due to the stress and unhealthy lifestyle (Haugstvedt et al., 2010). Several models (Pillonetto et al., 2001) are developed for type 1 diabetes patients, initially Bergma minimal model and its extension of three state model has been used as simplest but the majority of the components of the glucose-insulin interaction were ignored. The most complex model is Sorensen-model, defines the human blood glucose dynamics in a precise manner but it is hardly used because of its complexity. The closed loop glucose regulation (Chee and Fernando,

Corresponding Author: Arangasamy, R., Department of Electronics and Communication Engineering,

Paavai Engineering College, Namakkal, India 
2007) needs glucose sensor, insulin pump and control algorithm which is based on the glucose dimensions, it is capable to decide the necessary insulin dosage, to design an appropriate control an adequate model is necessary.

The proposed system is developed for Type-I diabetic patient using a simulation model based on Embedded control design, it has the closed loop feedback control algorithm with meal disturbance and time delay and compared with Harr Wavelet method. The proposed model gives the steady-state insulin concentration (in milli Units per $\mathrm{ml}$ blood) and the steady-state blood glucose concentration (in $\mathrm{mg}$ per $\mathrm{ml}$ )

\subsection{Blood Glucose Regulation}

When plasma glucose levels are elevated, insulin emission is stimulated. It raises the level of insulin in the blood, which increases the uptake of blood glucose through the tissues ( $\mathrm{Li}$ and $\mathrm{Hu}, 2007$; Danne et al., 2011). The improved depletion of glucose from the blood and interstitial fluid leads to a decrease in glucose concentration, which consequently produces a decrease in insulin secretion. Figure 1 represents the regulation of blood glucose and insulin. There are three ways through which glucose is eliminated from the blood. First, when $\mathrm{x}$ is elevated beyond a certain threshold $(\theta)$, it is excreted by the kidneys at a rate proportional to the gradient between $\mathrm{x}$ and $\theta$ and defined in Equation (1):

$$
\text { Renal Loss Rate }=\left\{\begin{array}{l}
\mu(x-\theta), x>\theta \\
0, x \leq \theta
\end{array}\right.
$$

Second, glucose leaves the blood to enter most cells through facilitated diffusion. The rate of glucose utilization depends only on the extracellular-tointracellular deliberation ascent (Cobelli and Mari, 1983). In the majority of conditions, researcher can ignore the intracellular deliberation (Lehmann and Deutsch, 1992; Andreassen et al., 1994) Equation (2):

Tissue Utilization Rate(Insulin-independent $)=\lambda x$

Third, the rate at which glucose is filling up by these cells is proportional to $\mathrm{x}$ as well as to the blood insulin concentration y Equation (3):

Tissue Utilization Rate $($ Insulin - dependent $)=$ vxy

Equating the inflow to the sum of the three outflows, we obtain the following mass balance equations for blood glucose which is defined in Equation (4):

$$
\mathrm{QL}=\left\{\begin{array}{l}
\lambda \mathrm{x}+\mathrm{vxy}, \mathrm{x} \leq \theta \\
\lambda \mathrm{x}+\mathrm{vxy}+\mu(\mathrm{x}-\theta), \mathrm{x}>\theta
\end{array}\right.
$$

Similarly, the mass balance equation for blood insulin is derived. The insulin is created by the pancreas at a rate dependent, on the plasma glucose level. However, if $\mathrm{x}$ falls below a certain threshold $(\Phi)$, insulin production reduces and is defined in Equation (5):

Insulin Production Rate $=\left\{\begin{array}{l}0, x \leq \varphi \\ \beta(x-\varphi), x>\varphi\end{array}\right.$

Insulin is ruined through a reaction relating the indulines enzyme, at a rate proportional to its concentration in blood is defined in Equation (6):

Insulin Destruction Rate $=\alpha y$

Combine Equation (5 and 6) researcher get the following equation concerning the steady-state level of $y$ to that of $x$ is defined in Equation (7 and 8):

$$
\begin{aligned}
& Y=0, x \leq \varphi \\
& \frac{\beta}{\alpha}=(x-\varphi), x \geq \varphi
\end{aligned}
$$

In Fig. 2 steady-state insulin concentration (in milli Units per $\mathrm{ml}$ blood) is plotted against the steady-state blood glucose concentration (in $\mathrm{mg}$ per $\mathrm{ml}$ blood). The insulin reaction to glucose is exposed as the valiant curve, while the lighter curve reveals the glucose mass balance equation (Salzsieder et al., 1985; Sorensen, 1985).

The parameter values employed in this calculation correspond to the normal adult: $\theta=2.5 \mathrm{mgml}^{-1}, \mu=7200$ $\mathrm{mlh}^{-1}, \lambda=2470 \mathrm{mlh}^{-1}, \mathrm{v}=139000 \mathrm{mU}^{-1} \mathrm{~h}^{-1}, \Phi=0.51$ mgml, $\beta \alpha=7600 \mathrm{mlh}^{-1}$ and $\mathrm{QL}=8400 \mathrm{mgh}^{-1}$. The intersection of the glucose and insulin curves yields the steady-state operating point labeled $\mathrm{N}$, where the glucose concentration is $0.81 \mathrm{mg} \mathrm{mL}^{-1}$ and the insulin concentration is $0.055 \mathrm{mU} \mathrm{mL}^{-1}$. This model is used to predict the steady-state operating levels of glucose and insulin that would arise from diabetes (Man and Cobelli, 2006).

In type-Idiabetes, the main defect is in the inability of the islet cells in the pancreas to produce sufficient insulin (Hovorka et al., 2004). The most common form of this disorder begins in childhood and, for this reason, it is called juvenile-onset diabetes (Del Favero et al., 2011). The other form begins in adulthood and is known as ketone prone diabetes. We can model this condition by lowering the sensitivity of the insulin response to glucose, Fig. 2b demonstrates the effect of reducing $\beta$ to $200 / 0$ of its normal value. 


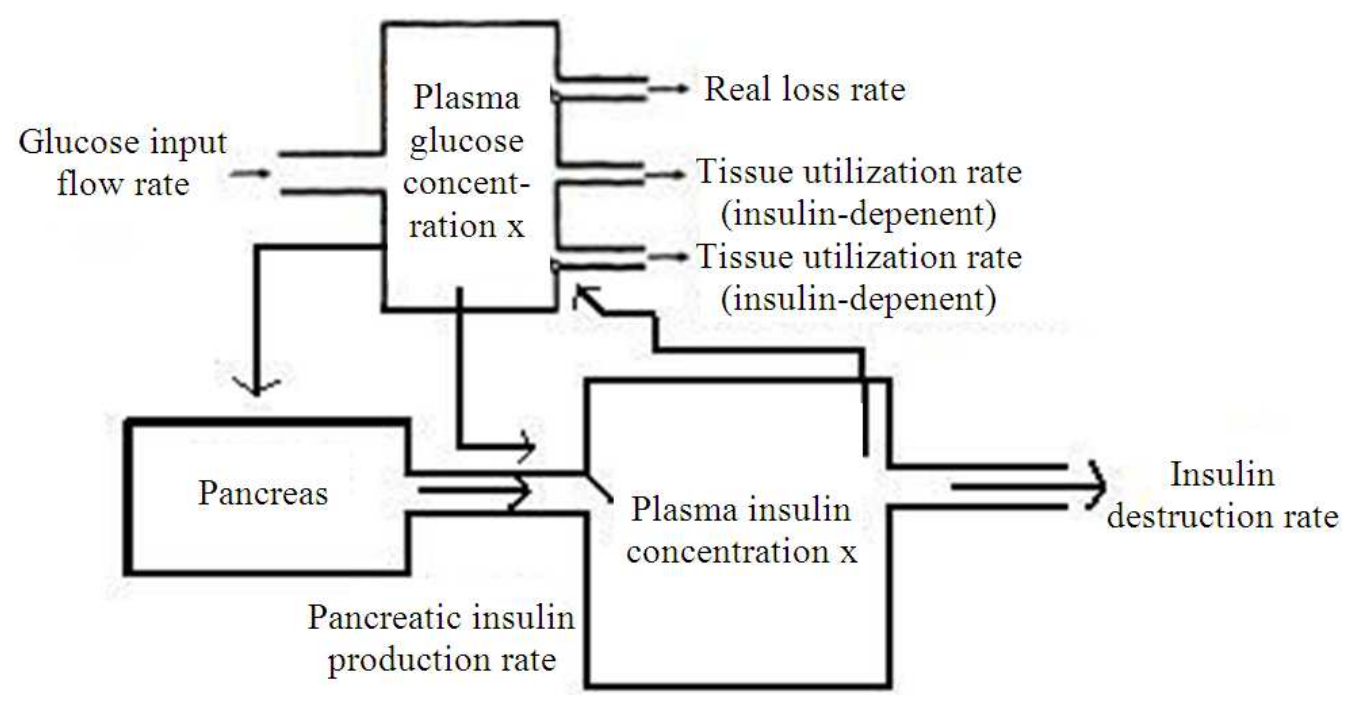

Fig. 1. Regulation of blood glucose and insulin

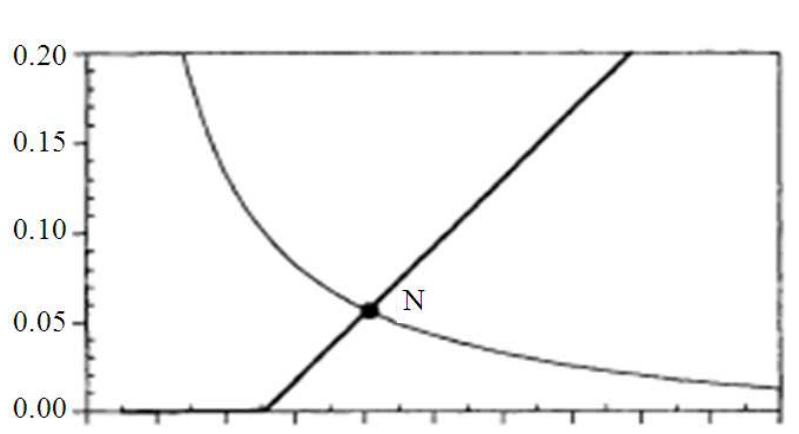

(a)

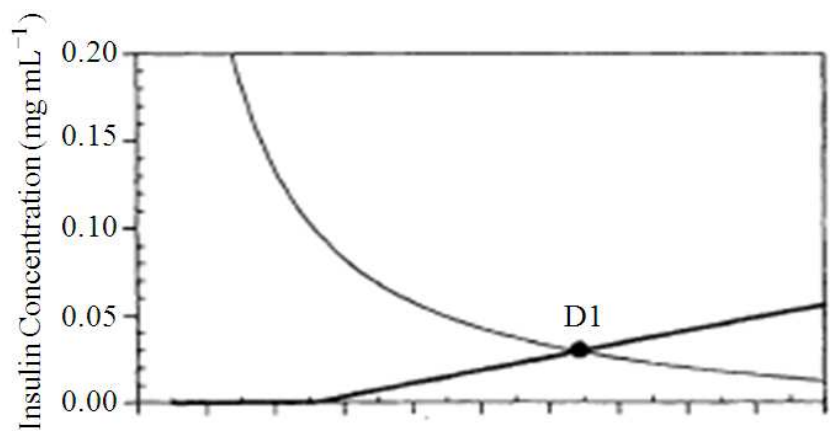

(b)

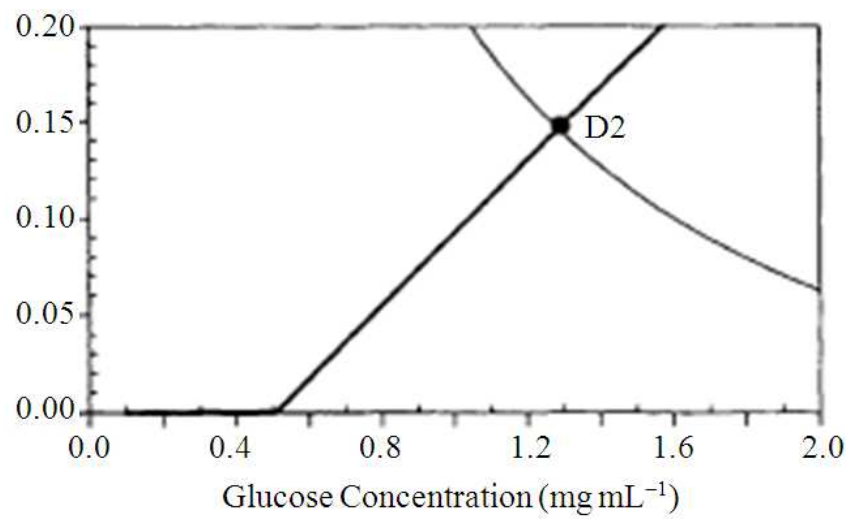

(c)

Fig. 2. Steady state analysis of blood glucose regulation (a) Normal (b) Type-2 diabetes (c) Type-1 diabetes

The new steady-state operating point is now established at D1, Resulting in a highly elevated blood glucose concentration of $1.28 \mathrm{mg} \mathrm{mL}^{-1}$ and plasma insulin concentration of $0.029 \mathrm{mU} \mathrm{mL}^{-1}$. 


\section{MATERIALS AND METHODS}

\subsection{Controller Design}

The blood glucose level of the patient is measured by the glucose sensor and is given as the input to the control system (Man et al., 2007). The protocols can be invasive, minimally invasive or non-invasive techniques. Insulin infusion pump acts as a controller to regulate the patient's blood glucose level. The insulin infusion pump will deliver the insulin according to the controller output with set value of time delay. The diabetic patient model was constructed using MATLAB software. It has two inputs, insulin delivery with nominal value of $22.3 \mathrm{mU}$ $\mathrm{min}^{-1}$ and meal disturbance with nominal value $0 \mathrm{mg}$ $\min ^{-1}$ and one measured output (Vicini et al., 1997; 1999). Based on the output of the patient model, change in infusion rate is calculated and is given as the input then the responses of the patient models are obtained. The feedback control system that could control the blood glucose within the nominal level with less settling time (Taylor et al., 1996; Pillonetto et al., 2001).

\subsection{Embedded Model System}

Embedded model system is shown in Fig. 3. There are three sensors used such as Glucose level sensor, pressure sensor, temperature sensor. The sensors will be of analog format. The researcher will use analog to digital converter to convert analog to digital values (Basu et al., 2003; 2006). Whenever the patient enters the lab, they need to be monitored and provided with exact solution with the help of database. The Patient glucose level goes beyond the normal level; automatically insulin will be injected with the help of controller section. In this article we will first look for the entry of the person. If the person enters the hospital then the lab test has to be conducted for them. The researcher will conduct only one test based on glucose level. This could be called as lab report.

Next we have to check the glucose, temperature, pressure of the person and maintain a database with all the details based on time. Finally the researcher will compare the test result with the original values. In this there are three conditions to be compared and monitored. The first one is normal level of glucose and the next is below level of glucose and the final one is higher level of glucose. From this comparison, we will come to know how much of insulin we need to inject to the person and this will be send as a feedback to the controller again for maintaining the glucose level in the blood the data's shown in Table 1.
The process will be repeated for a certain period of time to maintain a database because, whenever we need we will check the database with the help of time calculations and it will be easy for maintaining a patient detail in a database manner. The entry of the person is based on sensors then lab test has to be conducted for the patient and the details will be stored in EEPROM and as well as display's in LCD. Then with the help of sensors we will measure the information's and should displays in LCD. At the same time the measured values will be saved in EEPROM for comparison and as well as for getting the details of the patient at any time. Compare the stored information's of the sensors and lab test value with the help of EEPROM. With the comparison, we will provide suitable level of insulin to the patient. Repeat the process with the help of controller.

\subsection{Algorithm}

The algorithmic process is given below and defined in Equation (9):

$$
\begin{aligned}
& \mathrm{h}_{\mathrm{i}}(\mathrm{x})=\left\{\begin{array}{l}
1, \mathrm{x} \in\left[\varepsilon_{1}(\mathrm{i}), \varepsilon_{2}\right] \\
-1, \in\left[\varepsilon_{2}(\mathrm{i}), \varepsilon_{3}(\mathrm{i})\right] \\
0, \text { elsewhere }
\end{array}\right. \\
& \mathrm{i}=2^{\mathrm{j}}+\mathrm{k}+1, \mathrm{j} \geq 0,0 \leq \mathrm{k} \leq 2^{\mathrm{j}}-1
\end{aligned}
$$

Here:

$$
\begin{aligned}
& \text { Here, } \varepsilon_{1}=\frac{\mathrm{k}}{\mathrm{m}}, \varepsilon_{2}=\frac{\mathrm{k}+0.5}{\mathrm{~m}} \text {, and }, \varepsilon_{3}=\frac{\mathrm{k}+1}{\mathrm{~m}}, \\
& \mathrm{~m}=2^{\mathrm{j}}, \mathrm{j}=0,1,2, \ldots \mathrm{J}
\end{aligned}
$$

$\mathrm{J}$ is the maximum level of resolution $\mathrm{k}=0,1,2, \ldots \mathrm{m}-1$. $\mathrm{k}$ is the translation parameter. The index is $\mathrm{i}=\mathrm{m}+\mathrm{k}+1$. Maximum of $i$ is $M=2 m=2^{j+1}$. The collection points $\mathrm{x}_{1}=\frac{1-0.5}{2 \mathrm{~m}}, 1=0,1,2, \ldots 2 \mathrm{~m}$, are obtained by discretizing Haar function $h_{i}(x)$ by dividing the interval $[0,1]$ into $2 \mathrm{~m}$ parts of equal length $\Delta \mathrm{t}=\frac{1}{2 \mathrm{~m}}$ to get coefficient matrix $\mathrm{H}$ or order $2 m \times 2 m$ is defined in Equation (10):

$\mathrm{H}=\left[\begin{array}{l}1111 \\ 11-1-1 \\ 1-100 \\ 001-1\end{array}\right]$ 


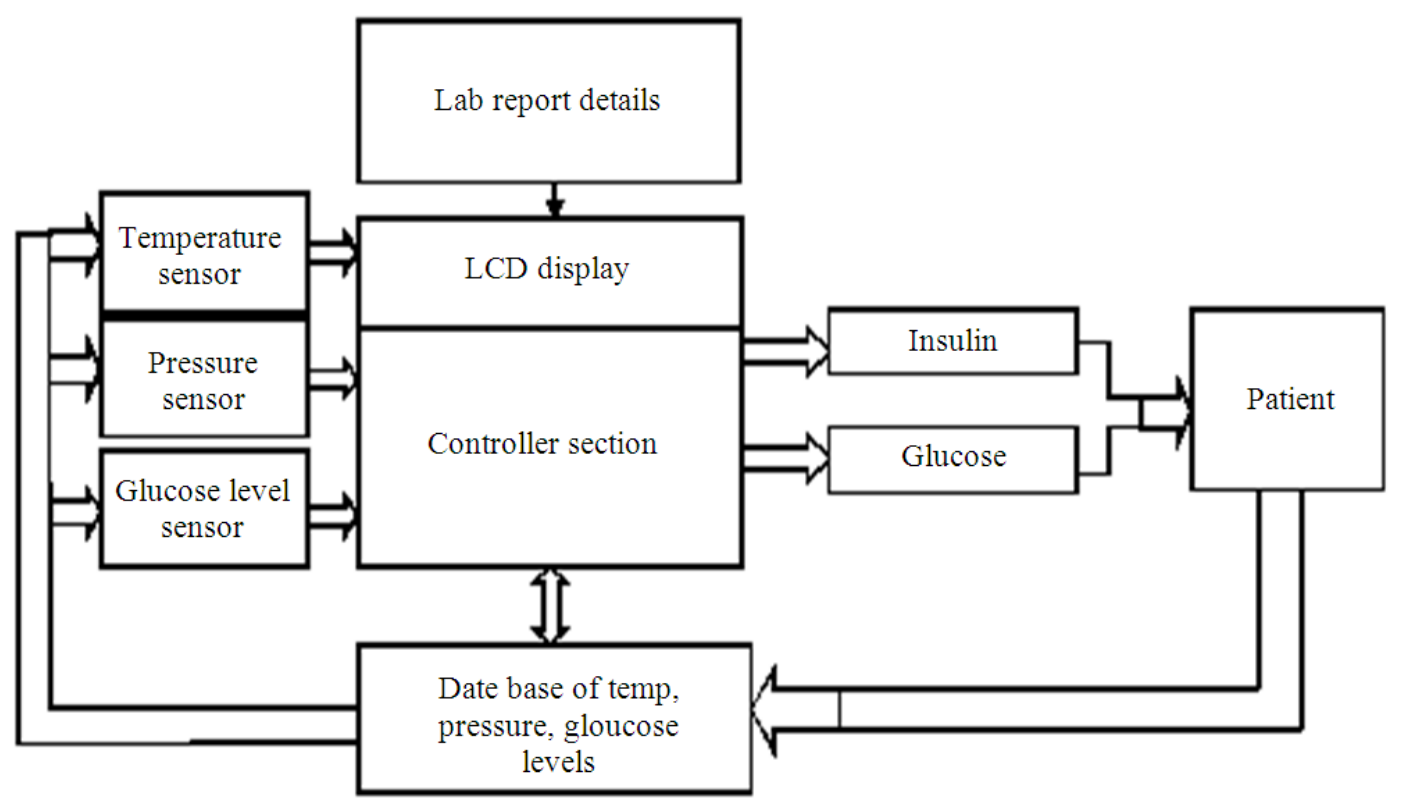

Fig. 3. Embedded model system

Table 1. Blood glucose levels

\begin{tabular}{lllll}
\hline BGL 70-89 mg dL & BGL 90-119 mg dL & BGL 120-179 mg DL & BGL $\geq 180 \mathrm{mg} \mathrm{dL}$ dL $^{-1}$ & Altering in infusion rate \\
\hline- & - & BGL $\uparrow$ by $>40 \mathrm{mg} / \mathrm{dL} / \mathrm{hr}$ & BGL $\uparrow$ & $\uparrow$ Infusion By “2 2 ” \\
- & BGL $\uparrow$ by $>20 \mathrm{mg} / \mathrm{dL} / \mathrm{hr}$ & BGL $\uparrow$ by $1-40 \mathrm{mg} / \mathrm{dL} / \mathrm{hr}$ & BGL $\downarrow$ by $1-40 \mathrm{mg} / \mathrm{dL} / \mathrm{hr}$ & $\uparrow$ Infusion By “ $\Delta$ ” \\
BGL $\uparrow$ & BGL $\uparrow$ by $1-20 \mathrm{mg} / \mathrm{dL} / \mathrm{hr}$ & BGL $\downarrow$ by $1-40 \mathrm{mg} / \mathrm{dL} / \mathrm{hr}$ & BGL $\downarrow$ by $41-80 \mathrm{mg} / \mathrm{dL} / \mathrm{hr}$ & No Infusion Change \\
BGL $\downarrow$ by $1-20 \mathrm{mg} / \mathrm{dL} / \mathrm{hr}$ & BGL $\downarrow$ by $21-40 \mathrm{mg} / \mathrm{dL} / \mathrm{hr}$ & BGL $\downarrow$ by $41-80 \mathrm{mg} / \mathrm{dL} / \mathrm{hr}$ & BGL $\downarrow$ by $81-120 \mathrm{~g} / \mathrm{dL} / \mathrm{hr}$ & $\downarrow$ Infusion By “ $\Delta$ ” \\
BGL $\downarrow$ by $>20 \mathrm{mg} / \mathrm{dL} / \mathrm{hr}$ & BGL $\downarrow$ by $>40 \mathrm{mg} / \mathrm{dL} / \mathrm{hr}$ & BGL $\downarrow$ by $>80 \mathrm{mg} / \mathrm{dL} / \mathrm{hr}$ & BGL $\downarrow$ by $>120 \mathrm{mg} / \mathrm{dL} / \mathrm{hr}$ & $\downarrow$ Infusion By “2 $2 \delta^{\prime}$ \\
\hline
\end{tabular}

Note, Haar wavelet is orthogonal and defined in Equation (11):

(i.e) $\int_{0}^{1} h_{i}(x) h_{1}(x) d x=\left\{\begin{array}{l}\frac{1}{m}, \text { for }, i=1 \\ 0, \text { for }, i \neq 1\end{array}\right.$

The operational matrix $\mathrm{P}$ which is a $2 \mathrm{~m}$.

Square matrix is defined in Equation (12):

$$
\mathrm{P}_{1, \mathrm{i}}(\mathrm{x})=\int_{0}^{1} \mathrm{~h}_{\mathrm{i}}(\mathrm{t}) \mathrm{dt}
$$

Then:

$$
\begin{aligned}
& P(x)=\int_{A}^{x} \int_{A}^{x} \ldots \int_{A}^{x} h_{i}(t) d t \\
& =\frac{1}{(\alpha-1)} \int_{A}^{x}(x-t)^{\alpha-1} h_{i}(t) d t \\
& \alpha=2,3 \ldots n, \text { and }, i=1,2 \ldots 2 m
\end{aligned}
$$

\subsection{Function approximation}

Haar wavelets are orthogonal; any square Integral Lebesgue function over $[0,1]$ can be expressed into Haar wavelets series as defined in Equation (13):

$$
(x)=\sum_{i=1}^{\alpha} a_{i} h_{i}(x)
$$

Here $\mathrm{a}_{\mathrm{i}}$ are Haar wavelet coefficients.

If $\mathrm{y}(\mathrm{x})$ be piecewise constant, then sum can be terminated to finite term and defined in Equation (14):

$$
\begin{aligned}
& \mathrm{y}\left(\mathrm{x}_{1}\right)=\sum_{\mathrm{i}=1}^{2 \mathrm{M}} \mathrm{a}_{\mathrm{i}} \mathrm{h}_{\mathrm{i}}\left(\mathrm{x}_{1}\right)=\mathrm{a}^{\mathrm{T}} \mathrm{H} \\
& \mathrm{a}^{\mathrm{T}}=\left\{\mathrm{a}_{1}, \mathrm{a}_{2, \ldots} \mathrm{a}_{2 \mathrm{M}}\right\}, \\
& \mathrm{H}=\left\{\mathrm{h}_{1}(\mathrm{x}), \mathrm{h}_{2}(\mathrm{x}), \ldots \mathrm{h}_{2 \mathrm{M}}(\mathrm{x})\right\}^{\mathrm{T}}
\end{aligned}
$$

The norm of error function) $\mathrm{v}(\mathrm{l})=\mathrm{y}_{\mathrm{app}\left(\mathrm{x}_{1}\right)}-\mathrm{y}_{\mathrm{ex}}\left(\mathrm{x}_{1}\right)$ is defined in Equation (15): 


$$
\|\mathrm{v}\|_{\mathrm{p}}=\left(\sum_{\mathrm{i}=1}^{2 \mathrm{M}}|\mathrm{v}(1)|^{\mathrm{p}}\right)^{\frac{1}{\mathrm{p}}}
$$

Local estimates is defined in Equation (16):

$\delta_{\mathrm{j}}=\left\|\frac{\mathrm{v}}{\mathrm{y}_{\mathrm{ex}}}\right\|_{\mathrm{x}}=\underset{1 \leq 1 \leq 2 \mathrm{M}}{\operatorname{Max}}\left|\frac{\mathrm{y}\left(\mathrm{x}_{1}\right)}{\mathrm{y}_{\mathrm{ex}}\left(\mathrm{x}_{1}\right)}-1\right|$

Global estimate is defined in Equation (17):

$\sigma_{\mathrm{j}}=\frac{\|\mathrm{v}\|_{2}}{2 \mathrm{M}}$

Absolute error is defined in 17 Equation (18):

$\mathrm{e}_{\mathrm{j}}=\underset{1 \leq 1 \leq 2 \mathrm{M}}{\operatorname{Max}}\left|\mathrm{y}_{\text {app }}\left(\mathrm{x}_{1}\right)-\mathrm{y}_{\mathrm{ex}}\left(\mathrm{x}_{1}\right)\right|$

\subsubsection{Application in Solving Linear ODE}

Consider $\mathrm{n}^{\text {th }}$ order linear ODE $\operatorname{Ly}(\mathrm{x})=\mathrm{f}(\mathrm{x}), \mathrm{A} \leq \mathrm{x} \leq \mathrm{B}, \mathrm{L}-$ Differential operator

Step1: The derivatives are defined in Equation $(18,19)$ :

$$
\mathrm{y}^{\mathrm{n}}(\mathrm{x})=\sum_{\mathrm{i}=1}^{2 \mathrm{M}} \mathrm{a}_{\mathrm{i}} \mathrm{n}_{\mathrm{i}}(\mathrm{x})
$$

Step2: For $\mathrm{a}<\mathrm{n}$ :

$$
y^{n}(x)=\sum_{i=1}^{n} a_{i} P_{n-\alpha, i}(x)+\sum_{\sigma=1}^{n} \frac{1}{\sigma !}(x-A)^{\sigma} y_{0}^{\alpha+\sigma}
$$

Step3: Substitute various derivatives as obtained in step (1) and (2) in the above equation, we get the numerical solution and defined in Equation (20 and 21):

$$
\begin{aligned}
& x^{\prime}=\sum_{i=1}^{2 M} a_{i} h_{i}(x) \\
& x=\sum_{i=1}^{2 M} a_{i} P_{1, i}(x)+x(0)
\end{aligned}
$$

Where:

$$
\mathrm{P}_{1, \mathrm{i}}(\mathrm{t})=\int_{0}^{\mathrm{x}} \mathrm{h}_{\mathrm{i}}(\mathrm{t}) \mathrm{dt}
$$

\subsubsection{Method of Solution}

Consider the Equation (21 to 24 ) for deriving the solution:

$\mathrm{C}_{\mathrm{G}} \frac{\mathrm{dx}}{\mathrm{dt}}=\mathrm{U}(\mathrm{t})+\mathrm{QL}-\lambda \mathrm{x}-\mathrm{vxy}$

Sub (20) and (21) in (23):

$\mathrm{C}_{\mathrm{G}}\left[\sum_{\mathrm{i}=1}^{2 \mathrm{M}} \mathrm{a}_{\mathrm{i}} \mathrm{h}_{\mathrm{i}}(\mathrm{x})\right]=\mathrm{U}(\mathrm{t})+\mathrm{QL}-$

$\lambda\left[\sum_{\mathrm{i}=1}^{2 \mathrm{M}} \mathrm{a}_{\mathrm{i}} \mathrm{P}_{1, \mathrm{i}}(\mathrm{x})+\mathrm{x}(0)\right]-$

$\mathrm{v}\left[\sum_{\mathrm{i}=1}^{2 \mathrm{M}} \mathrm{a}_{\mathrm{i}} \mathrm{P}_{1, \mathrm{i}}(\mathrm{x})+\mathrm{x}(0)\right] \mathrm{y}$

Figure 4 gives the details of Harr wavelet mathematical approach controller output without giving insulin for every $30 \mathrm{~min}$ duration.

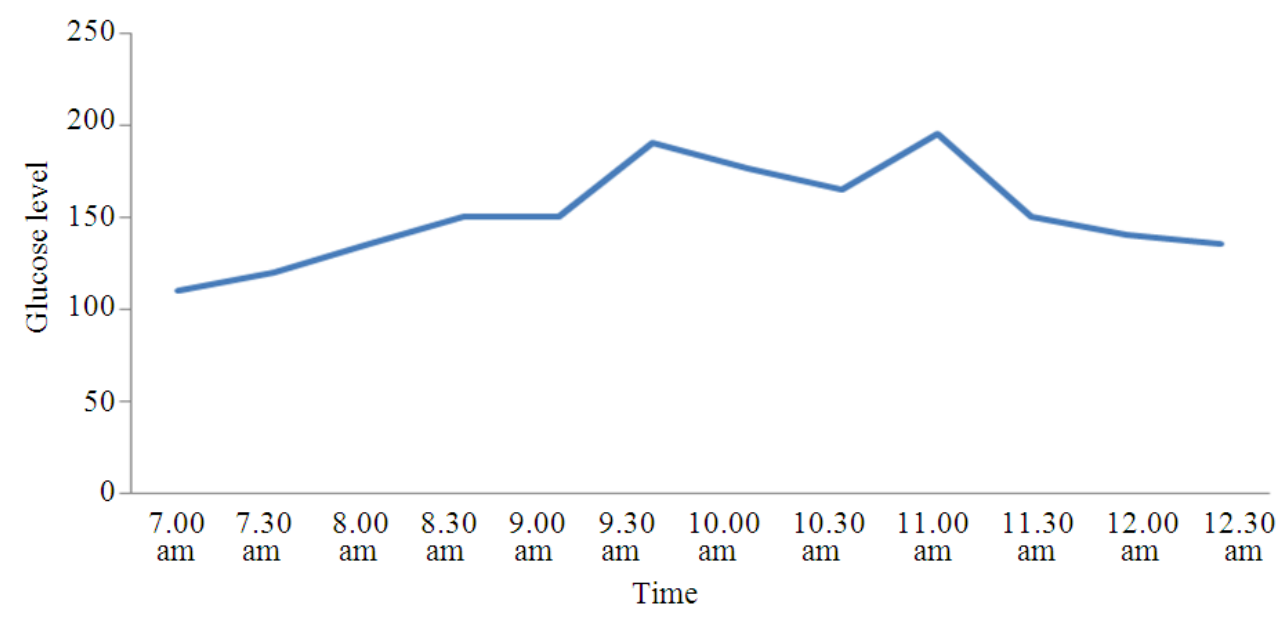

Fig. 4. Blood glucose without insulin 


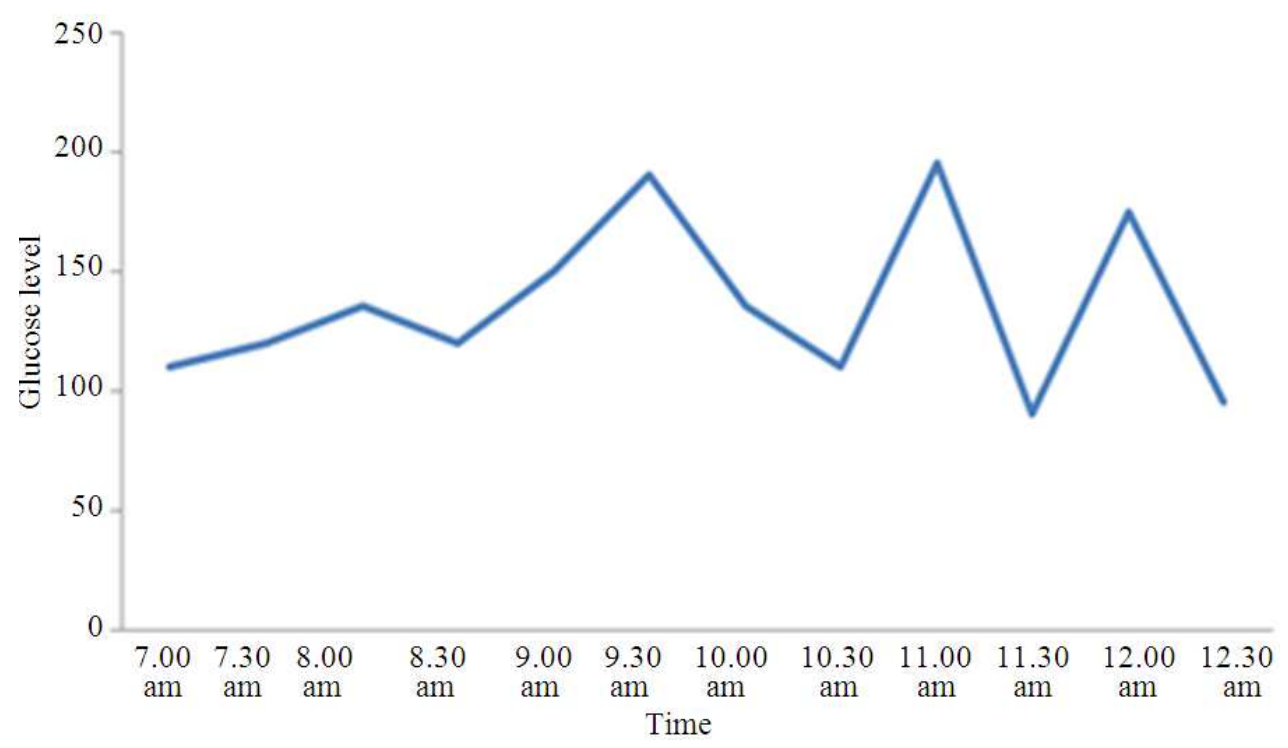

Fig. 5. Blood glucose with insulin and100 gm meal disturbance

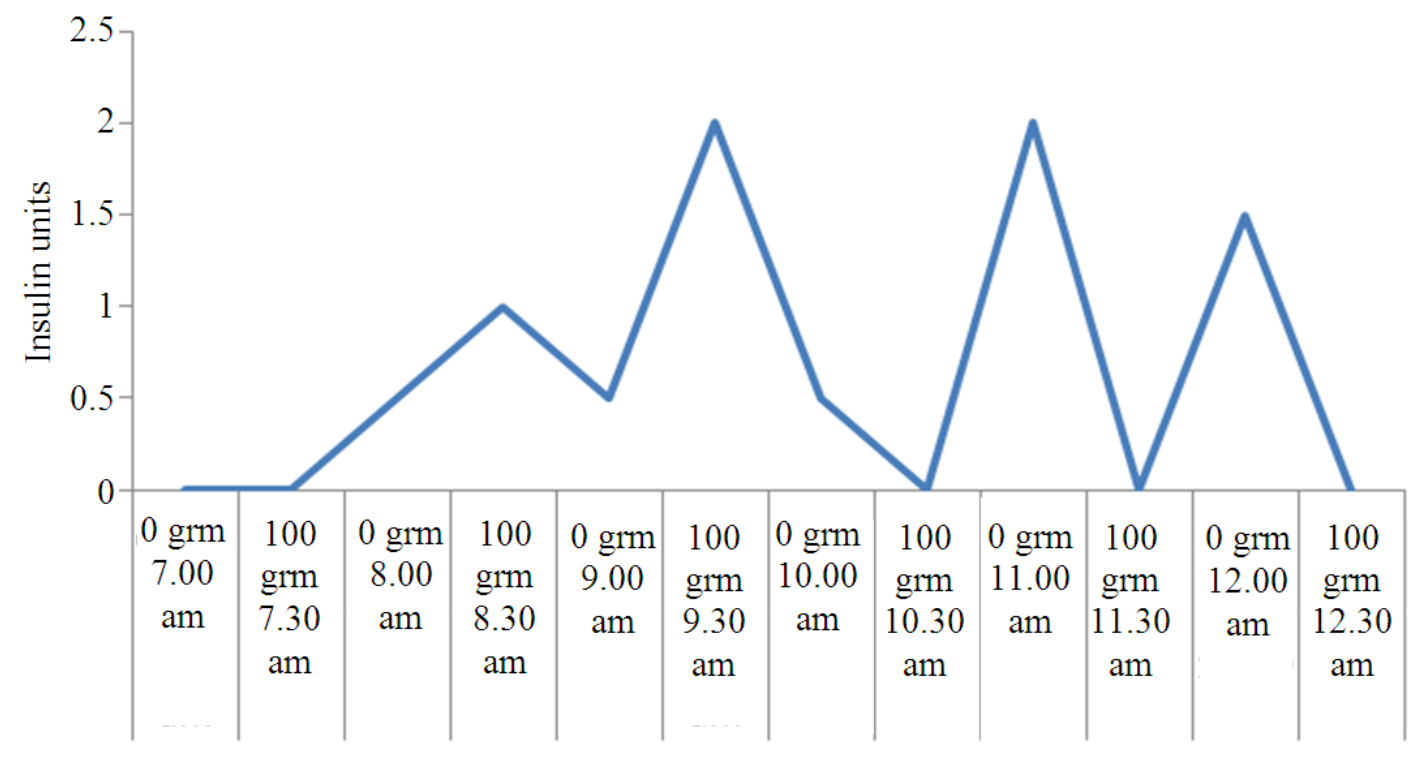

Meal w.r.to Time

Fig. 6. Insulin and $100 \mathrm{gm}$ meal

Figure 5 gives the details of Harr wavelet mathematical approach controller output with giving insulin for every $30 \mathrm{~min}$ duration and the meal disturbance is $100 \mathrm{gm}$ for very one hour.

As per the standard Glucose Tolerence test, Fig. 6 gives the details of Harr wavelet mathematical approach controller output by giving insulin for every
30 min duration with respect the meal and blood glucose level.

\section{RESULTS}

This model allows us to predict the effect of the various control signals on glucose production as well as 
the insulin independent and dependent components of glucose utilization in addition; hepatic insulin extraction can also be predicted. The model consists of a glucose and insulin subsystem. The glucose system is described by a two-compartment model, the first representing glucose mass in plasma and rapidly equilibrating tissues and the second the slowly equilibrating tissues.

Glucose utilization has both an insulin-independent component occurring in plasma and an insulindependent component in the second compartment. The insulin-independent utilization is constant and represents glucose uptake by CNS and erythrocytes, while the insulin-dependent utilization is controlled nonlinearly by glucose in the tissue compartment and insulin in the interstitial fluid. Endogenous glucose production control by glucose and insulin implements recent knowledge, in particular it assumes that fast suppression occurs through a portal insulin signal, while slower inhibition by a delayed insulin signal, possibly a surrogate of interstitial fluid/free fatty acids signal. A novel form of glucose transit from side to side the gastro-intestinal tract is used to describe glucose ingestion and absorption. This feature is important because previous simulation models either allowed only intravenous glucose administration.PIC simulator IDE is used as a simulator for this project. Modules used in this simulation are LCD, Microcontroller view and EEPROM for seeing the desired sensor values and outputs. In this the LCD is mainly used to display the contents and microcontroller view is used for setting the sensor values manually because it is only a simulation view and EEPROM is used to display the sensor values on each address and as well as output's on each slot (Fig. 7).

The insulin system is described by a twocompartment model. Degradation is assumed to occur linearly in the periphery while liver degradation is assumed to be time-varying in agreement with current knowledge. Insulin secretion is assumed to be dependent on both plasma glucose concentration and its rate of change as with all models, nearby are a number of restrictions.

The most important is that count regulatory hormones, such as glucagon, epinephrine and growth hormone, have not been considered. This will be considered in future model developments. This will be also important for extending the model to type 1 diabetes. Another limitation concerns the glossocentric nature of the model; the role of other stimulate substrates like free fatty acids and their interaction with glucose and insulin is not considered. Finally, when modeling daily life, it would be important to include diurnal variation of parameters A new in silica model of the glucose-insulin regulatory system has been presented. Focusing on quantitating physiological events after a meal is of obvious importance because this route is used in everyday life. The postprandial state has also been intensively investigated in recent years; thus, one can take advantage of all new quantitative knowledge that has become available. The model is made by a number of parsimonious sub models describing the various unit processes that have been identified using a forcing function strategy. This falls into 3 basic components of the insulin regimen:

- A correction dose based on the difference between actual BG level and a target Blood glucose level, divided by a correction factor of insulin sensitivity (in BG counts per $u$ nit of insulin, or more correctly $\mathrm{mg} / \mathrm{dl} / \mathrm{unit}$ )

- A meal bolus or a single large dose of insulin to cover a meal about to be eaten based on a count of

- carbohydrate grams of the food multiplied by the insulin-to-carb-ratio (I/c) in units per gram

- Basal insulin or slow release (background) insulin that a person needs all the occasion The new insulin analogs such as Lantus and Levimur last for 12 to $24 \mathrm{~h}$ and give a low slow dose of background insulin (Fig. 8 and 9)

A formula frequently educated to diabetic children to calculate their insulin requirement before a meal is:

$$
\begin{aligned}
& \text { Pre }- \text { meal insulin injection (in units) } \\
& =\text { Correction dose }+ \text { meal bolus }
\end{aligned}
$$

where, the correction dose $=(($ Actual BG level $)-($ target BGlevel) $) /($ Insulin sensitivity factor in BG counts per unit).

The meal bolus $=($ grams of carbs in food about to be eat/(Insulin to carb proportion used for that meal).

Here are the key variables in the algorithms definitions are.

\subsection{Target Value}

The desired intermediate value (often $110 \mathrm{mg} \mathrm{dL}^{-1}$ ) used to calculate a precise correction bolus (as opposed to the upper and lower values of a target range). 


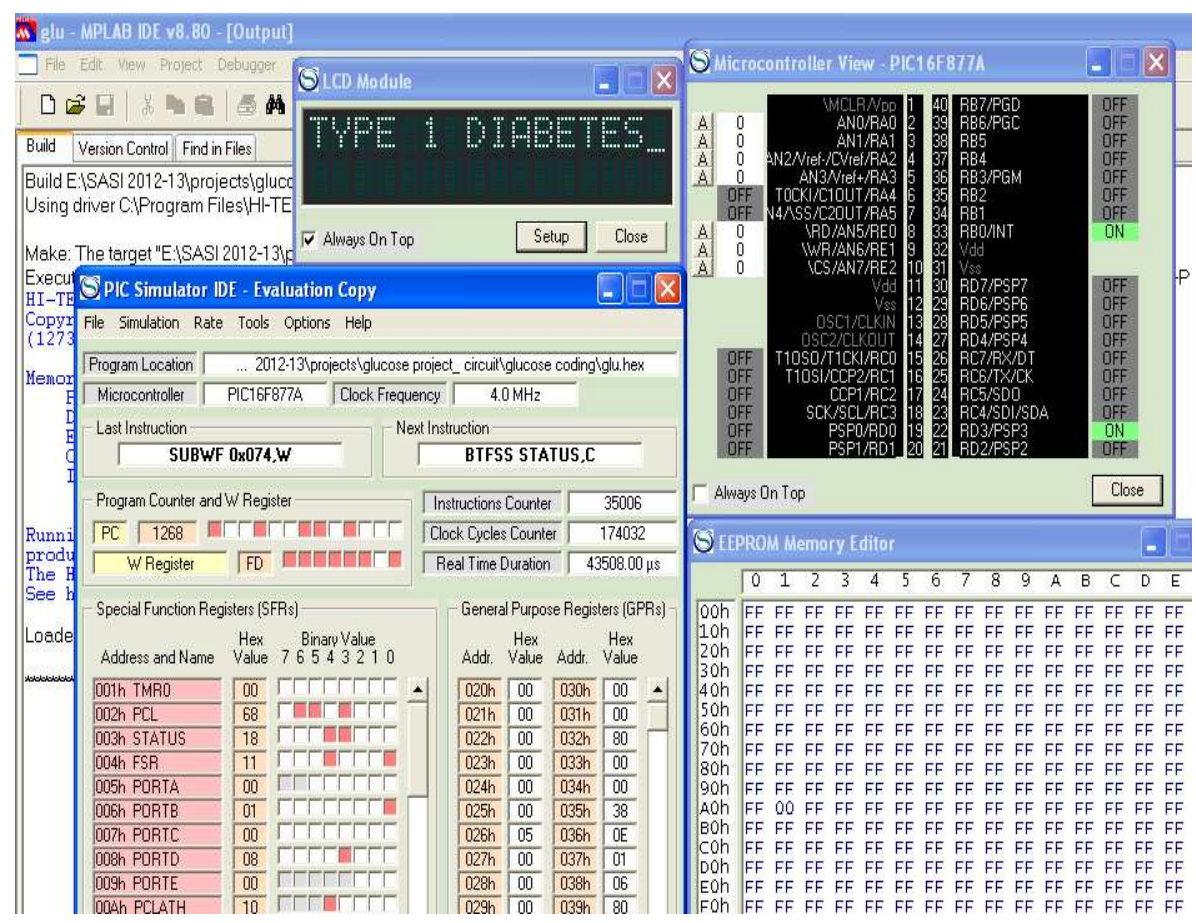

Fig. 7. Type 1 diabetes

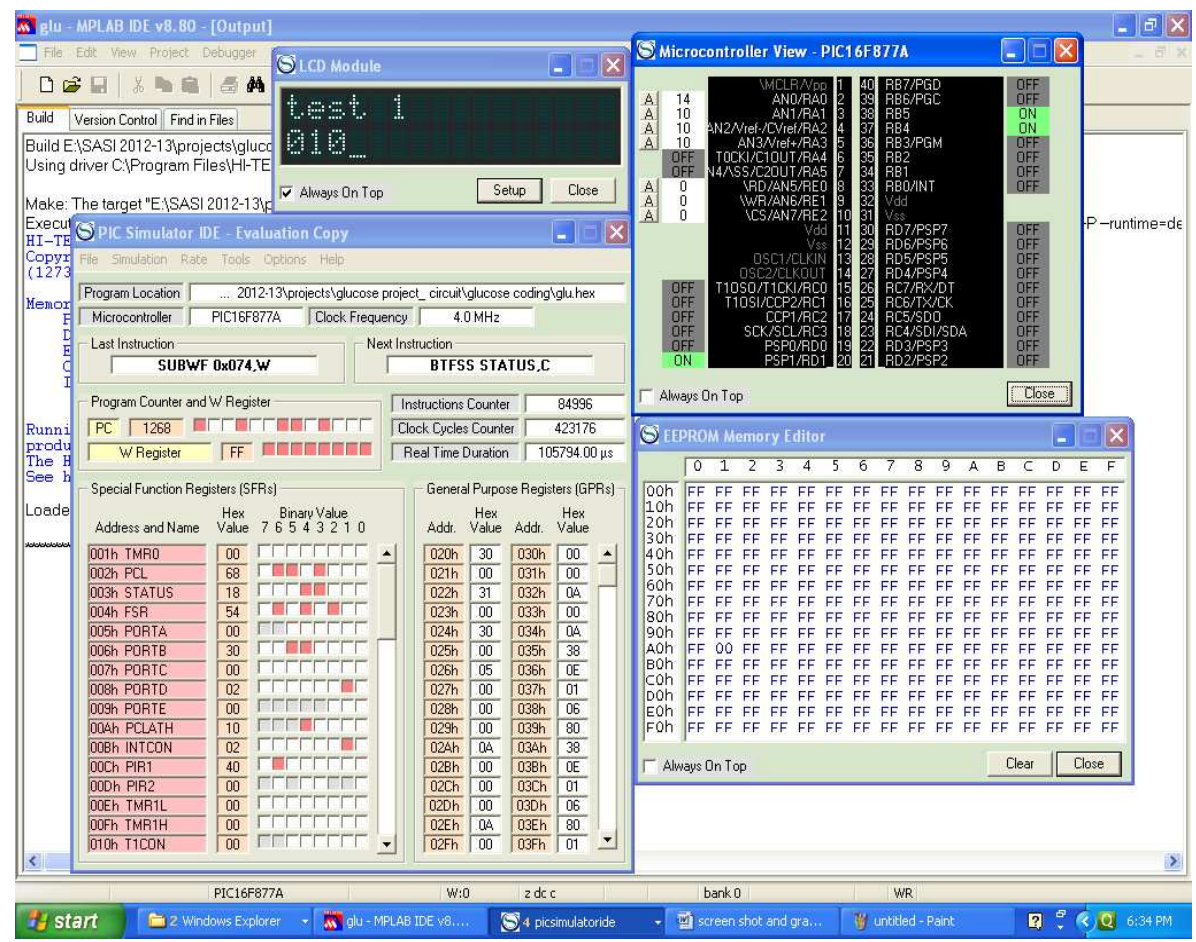

Fig. 8. Laboratory test 1 
Arangasamy, R. et al. / American Journal of Applied Sciences 11 (3): 433-447, 2014

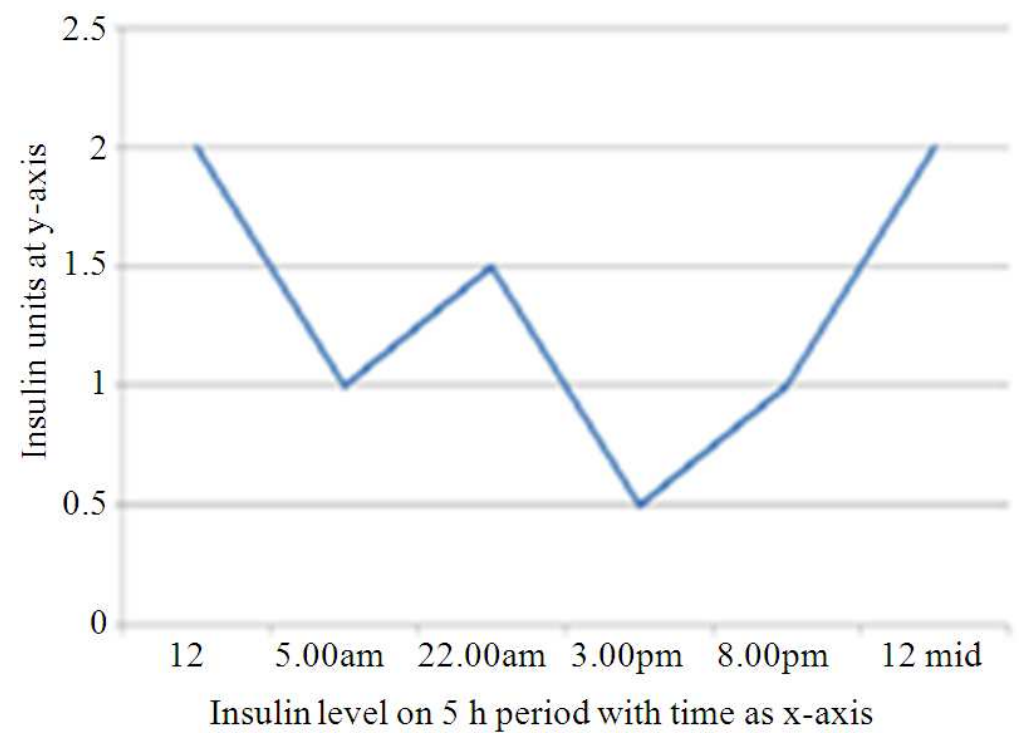

Fig. 9. Insulin level on $5 \mathrm{~h}$ period

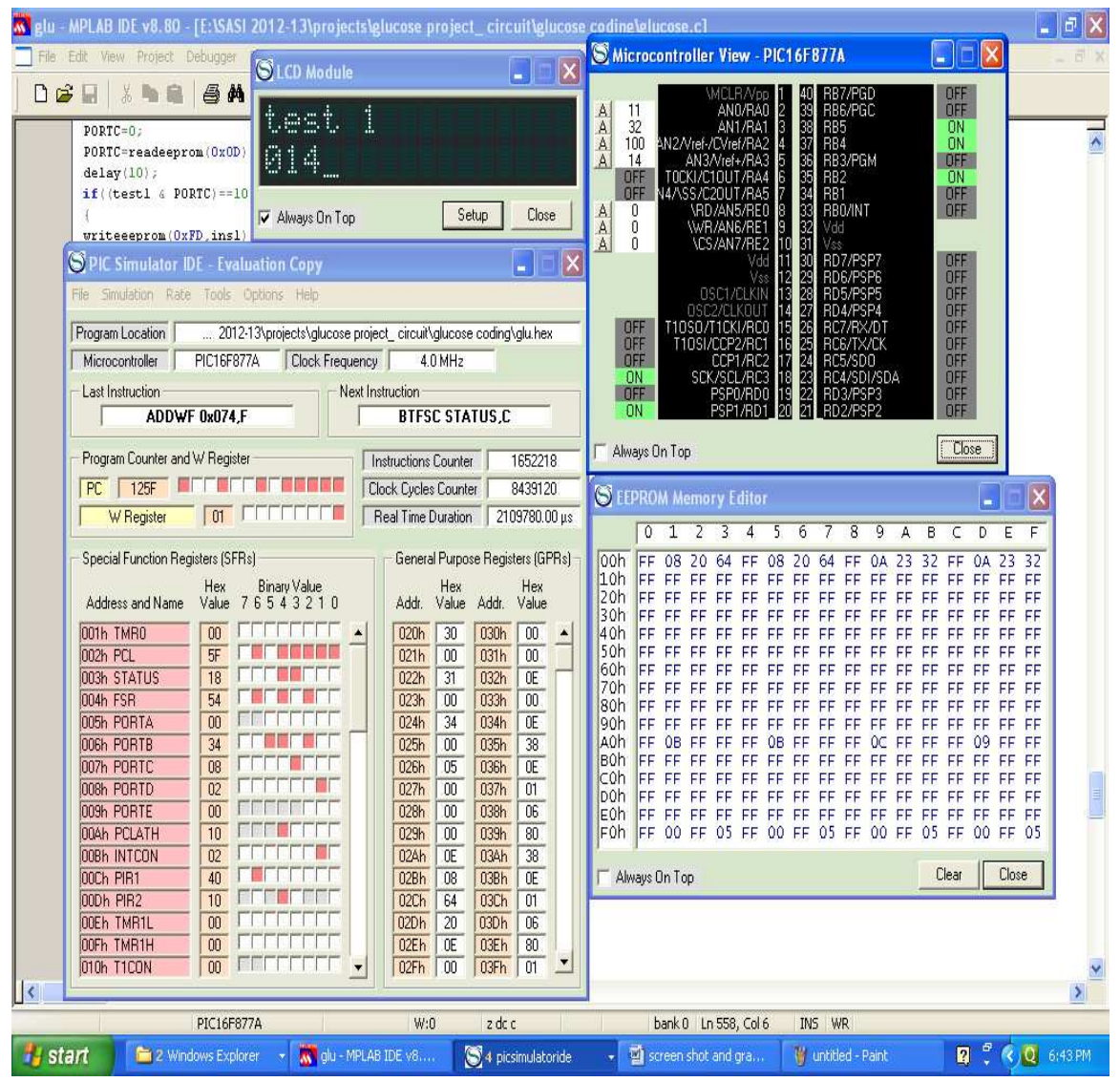

Fig. 10. Laboratory test 2 


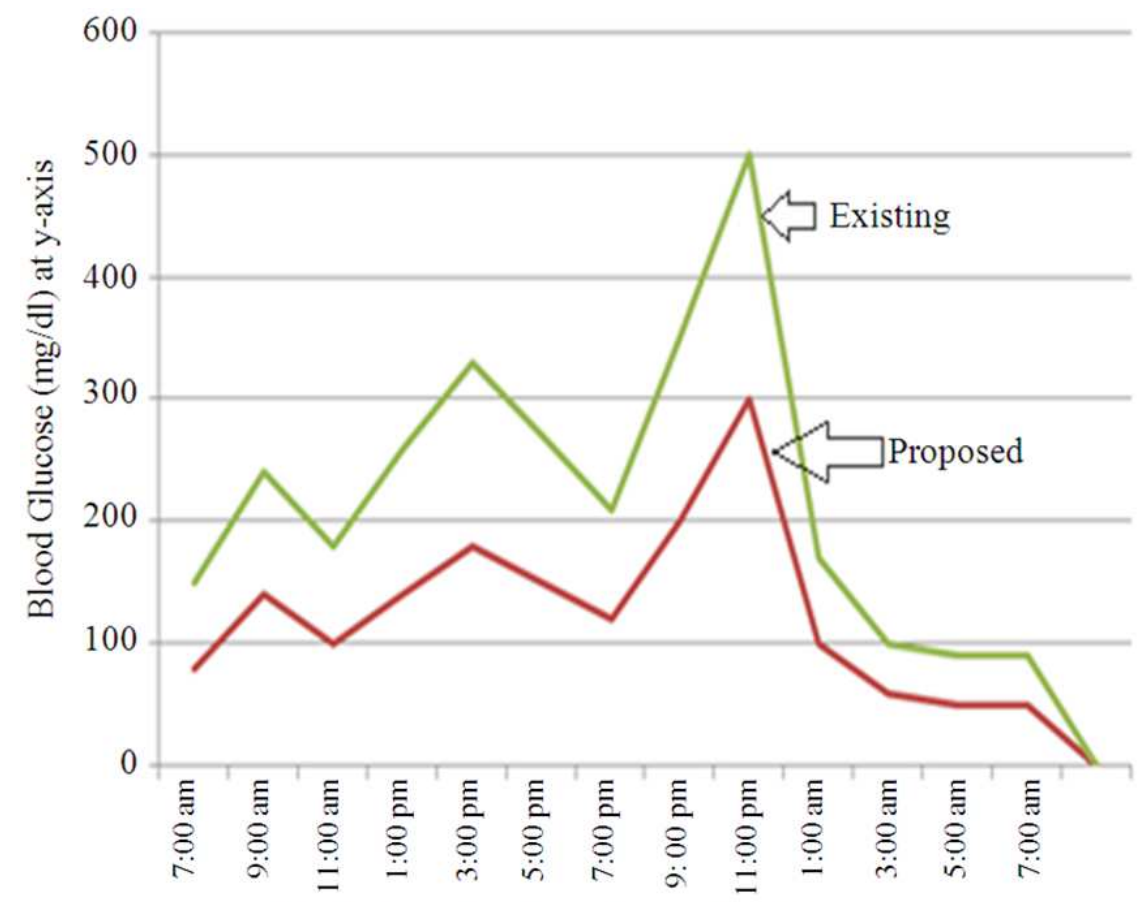

Blood glucose level on $6 \mathrm{~h}$ periods with time as $\mathrm{x}$-axis

Fig. 11. Existing and proposed blood glucose level

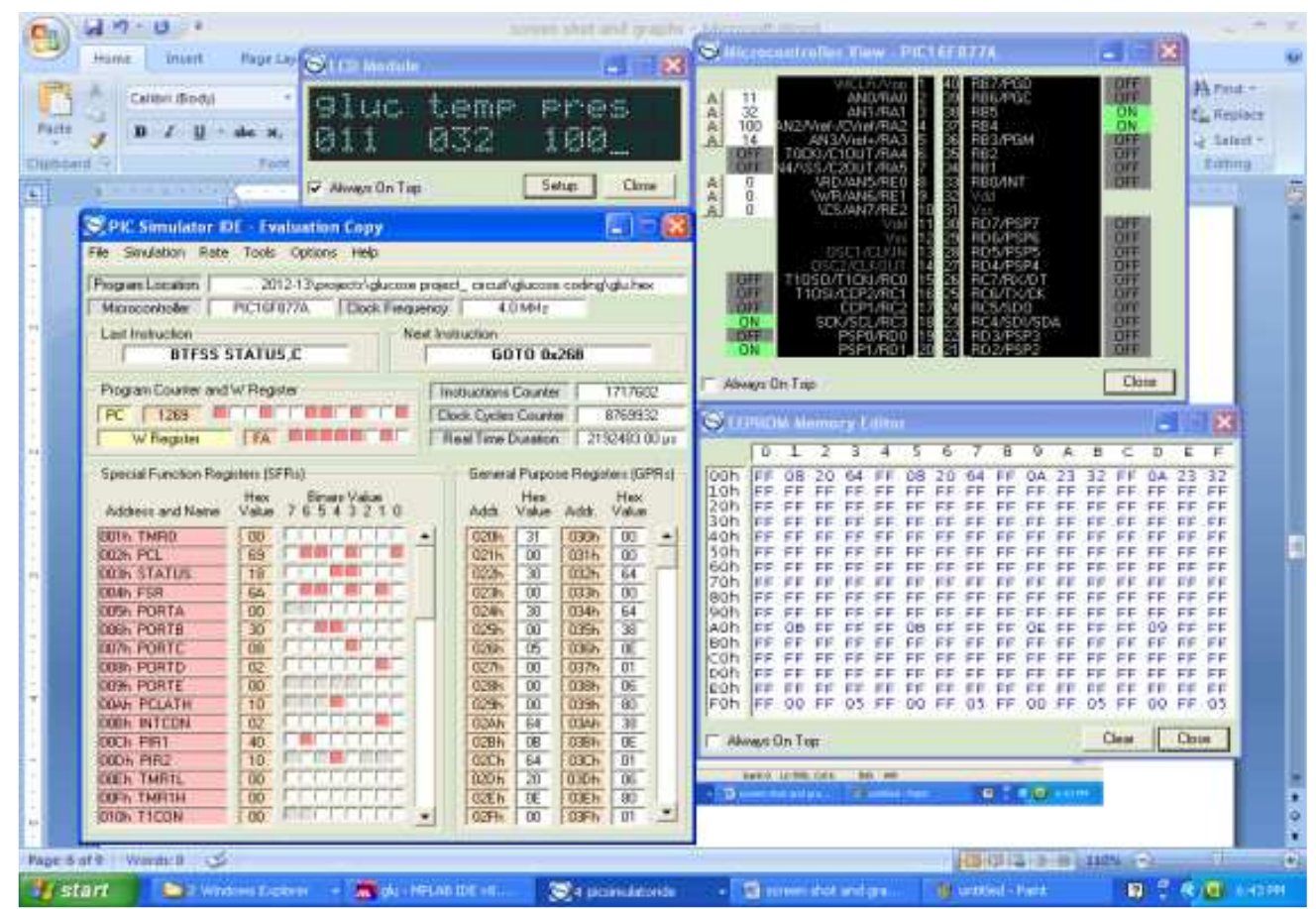

Fig. 12. Glucose temperature pressure output 


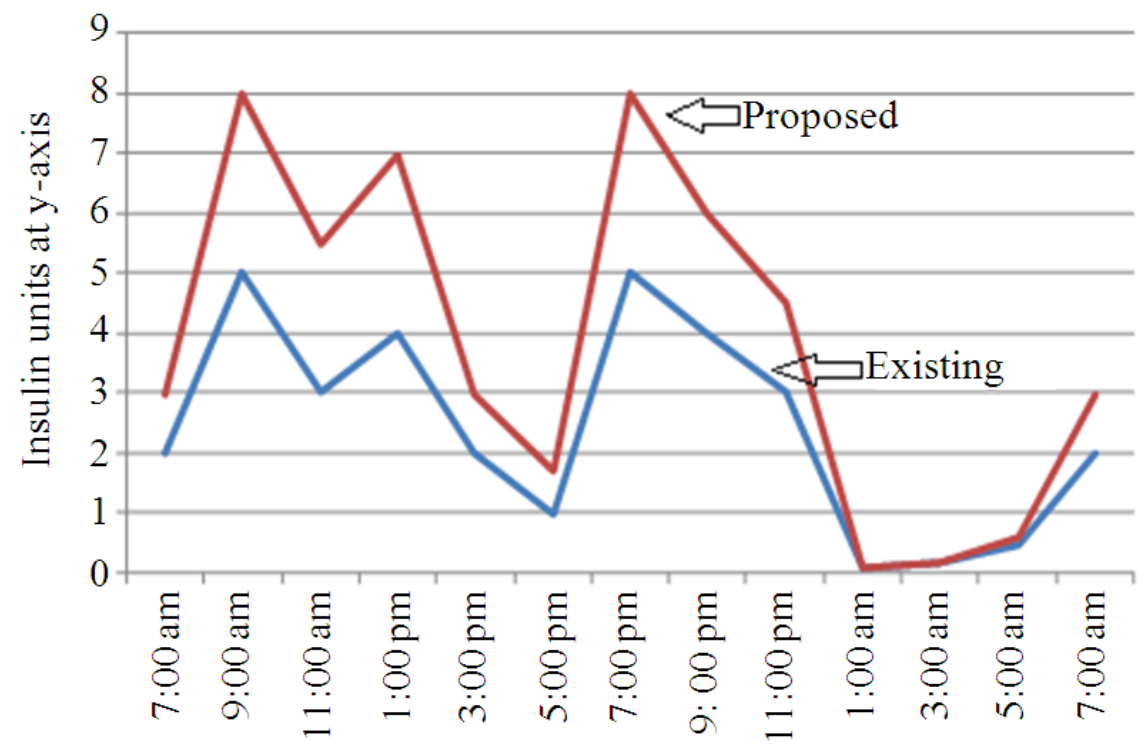

Insulin level on $6 \mathrm{~h}$ periods with time as $\mathrm{x}$-axis

Fig. 13. Existing and proposed glucose levels

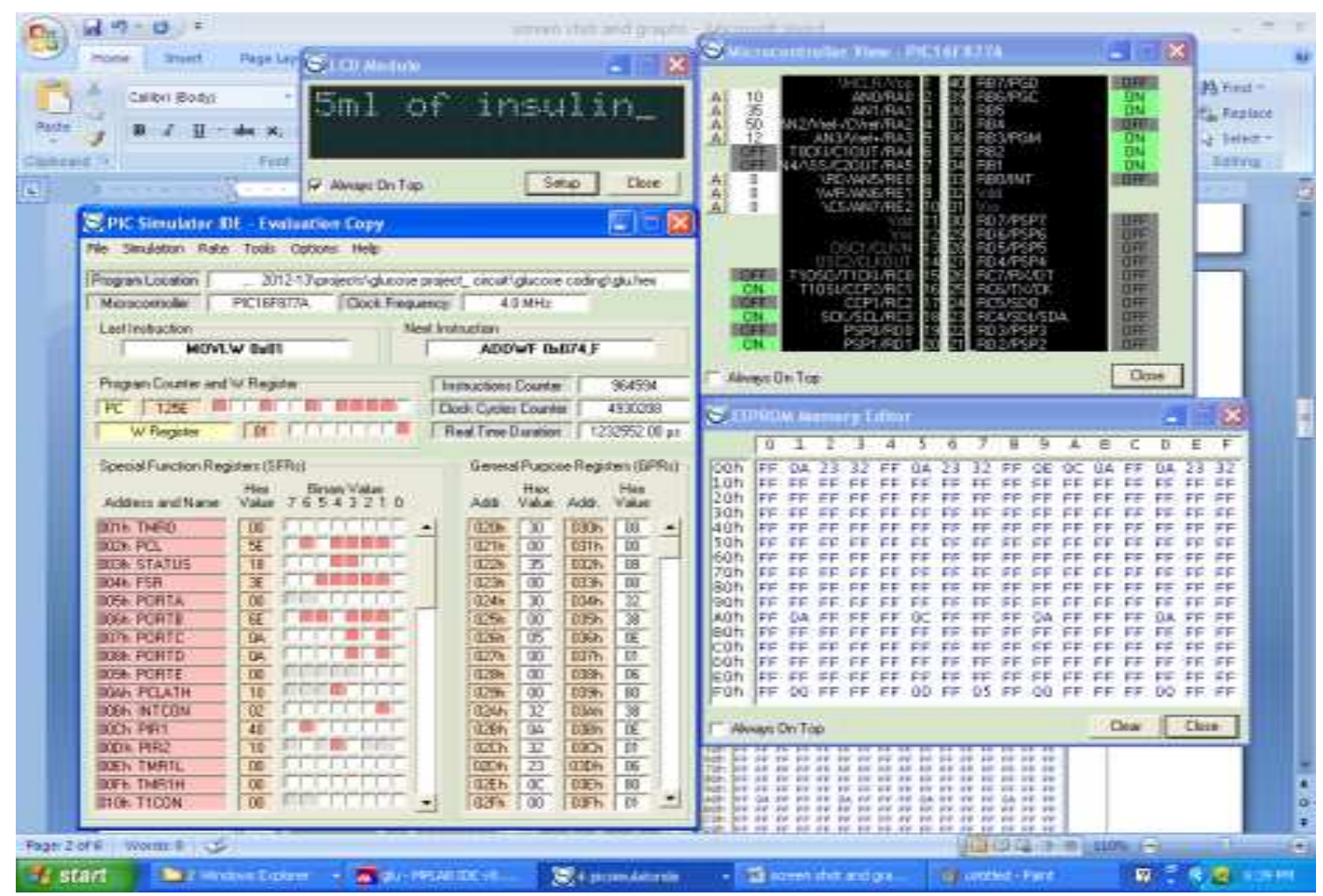

Fig. 14. Insulin to be injected 


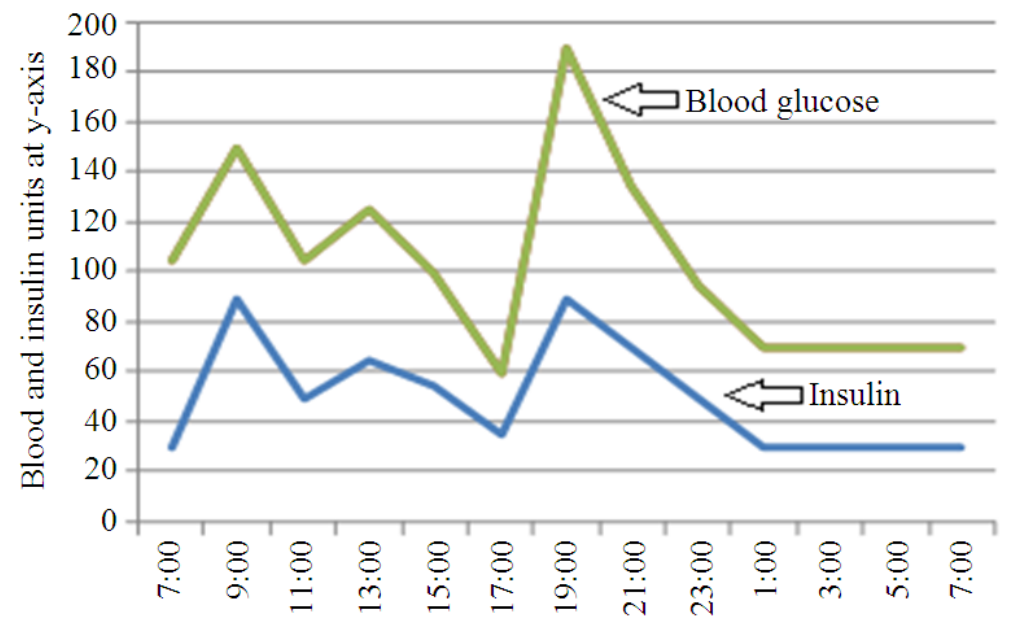

Blood Glucose insulin level on $6 \mathrm{~h}$ periods with time as $\mathrm{x}$-axis

Fig. 15. Blood and insulin levels

\subsection{Insulin Sensitivity Factor}

Ratio of the predictable impact of insulin on the blood sugar given in $\mathrm{mg} / \mathrm{dl}$ per unit of insulin. Example, one persons sensitivity might be a drop in $60 \mathrm{mg} \mathrm{dL}^{-1}$ of blood sugar per unit of insulin given.

\subsection{Insulin-to-Carb Ratio}

The ratio of grams of glucose enclosed by one unit of insulin, generally given as grams per unit. The ratio is particular to one meal for that one diabetic person (breakfast $=15 \mathrm{~g} \mathrm{u}^{-1}$, lunch $=19 \mathrm{~g} \mathrm{u}^{-1}$ ).

\subsection{Basal Rate}

The rate of incessant insulin liberation for basal requirements equivalent to the total daily basal insulin such as from Lantus or Levimur.

Enter the insulin pump. Compared to the long acting insulin, the continuous infusion of fast-acting insulin for basal needs offers these benefits:

- $\quad$ Accurate low rate delivery making CSII possible

- Elimination of the peaks and valleys of those insulin profiles, the dynamic ability to dial back the basal insulin to react to an impending low blood sugar, Control and memory of the basal profile, to actually "fit" the basal profile to the specific needs of individuals

The same characteristics that make for a good robust of basal insulin also benefit the pump user for all insulin needs:
- Accurate small boluses, as needed for more precise carb counting

- $\quad$ Precise correction doses, allowing partial units (0.05 to 0.1 units) and lower BG targets instead of the upper level of a target range

- Achieving tighter blood glucose manage, which ultimately realize a lower $\mathrm{HbA} 1 \mathrm{c}$

- Hence, the algorithm for interfacing with the insulin pump is the same as with intensive insulin therapy, but utilizes a basal rate of truthtemporary insulin. The explanation parameters, as shown in the "data store" boxes in the diagram, are all required to control the insulin pump and preserve be "learned" by the insulin pump with the use of adaptive variables (Fig. 10-15)

\section{DISCUSSION}

The proposed system is controlled by the operation of two methods, one is Harr wavelet mathematical approach and the other is Embedded based non-linear parametric controller algorithm. In each method a proposed algorithm is fed to the system which yields two different outputs. The outcome of this the embedded non-linear method gives $97 \%$ accuracy when compared to the standard gold chart and Harr wavelet mathematical proved $89.09 \%$ accuracy.

\section{CONCLUSION}

In this article, the modeling strategy is novel and has taken advantage of a unique meal data set both in normal 
and type 1 diabetes in which plasma concentrations, relevant glucose and insulin fluxes during a meal were available. The model should prove valuable as simulator in several situations dealing with the patho physiology of diabetes. The availability of a simulation model of the glucose-insulin control system during meals and normal daily life is highly desirable for studying the patho physiology of diabetes and in particular for the design and estimation of glucose sensors, insulin combination algorithms and decision support systems for treating diabetes, in particular type 1 (insulin dependent). The researcher simulated and compared with Harr wavelet mathematical model for hypoglycemia by injecting an overabundance of insulin into the blood. However, the embedded model proved $97 \%$ and mathematical Harr wavelet model proved $89.09 \%$ of accuracy of the assured values of our experiments, only simulated a temporary hypoglycemia in a normal concentration levels, rates and parameters for this particular system. This results in an overproduction of insulin that drives down the plasma glucose concentration in to normal level.

\section{REFERENCES}

Anantha, S.K., S.K. Natarajan and S.S. Dash, 2013. Modeling and simulation of fuzzy based automatic insulin delivery system. J. Comput. Sci., 9: 11331139. DOI: $10.3844 /$ jessp.2013.1133.1139

Andras, G., K. Levente, H. Tamas and B. Balazs, 2009. Investigating a novel model of human blood glucose system at molecular levels from control theory. Acta Univ. Sapientiae Electr. Mechan. Eng., 1: 77-92.

Andreassen, S., J.J. Benn, R. Hovorka, K.G. Olesen and E.R. Carson, 1994. A probabilistic approach to glucose prediction and insulin dose adjustment: Description of metabolic model and pilot evaluation study. Comput. Methods Programs Biomed., 41: 153-165. DOI: 10.1016/01692607(94)90052-3

Basu, R., B.D. Camillo, G. Toffolo, A. Basu and P. Shah et al., 2003. Use of a novel triple tracer approach to asses postprandial glucose metabolism. Am. J. Physiol. Endocrinol. Metab., 284: E55-E69. PMID: 12485809

Basu, R., C.D. Man, M. Campioni, A. Basu and G. Klee et al., 2006. Mechanisms of postprandial hyperglycemia in elderly men and women: Gender specific differences in insulin secretion and action. Diabetes, 55: 2001-2014.
Bergenstal, R.M., W.V. Tamborlane, A. Ahmann, J.B. Buse and G. Dailey et al., 2010. Effectiveness of sensor-augmented insulin-pump therapy in type 1diabetes. N. Engl. J. Med., 363: 311-320. DOI: 10.1056/NEJMoa1002853

Chee, F. and T. Fernando, 2007. Closed-Loop Control of Blood Glucose. 1st Edn., Springer, Berlin, ISBN-10: 3540740309, pp: 157.

Cobelli, C. and A. Mari, 1983. Validation of mathematical models of complex endocrinemetabolic systems: A case study on a model of glucose regulation. Med. Biol. Eng. Comput., 21: 390-399. DOI: 10.1007/BF02442625

Danne, T., O. Kordonouri, M. Holder, H. Haberland and S. Golembowski et al., 2011. Prevention of hypoglycemia by using low glucose suspend function in sensor-augmented pump therapy. Diabetes Technol. Ther., 13: 1129-1134. DOI: 10.1089/dia.2011.0084

Del Favero, S., G. Pillonetto, C. Cobelli and G. De Nicolao, 2011. A novel nonparametric approach for the identification of the glucose-insulin system in Type 1 diabetic patients. Proceedings of the 18th IFAC World Congress, Aug. 28-Sept. 2, Milano, Italy, pp: 8340-8346. DOI: 10.3182/20110828-6-IT1002.01929

Haugstvedt, A., T. Wentzel-Larsen, M. Graue, O. Søvik and B. Rokne, 2010. Fear of hypoglycaemia in mothers and fathers of children with Type 1 diabetes is associated with poor glycaemic control and parental emotional distress: A populationbased study. Diabet. Med., 27: 72-78. DOI: 10.1111/j.1464-5491.2009.02867.x

Hovorka, R., V. Canonico, L.J. Chassin, U. Haueter and M. Massi-Benedetti et al., 2004. Nonlinear model predictive control of glucose concentration in subjects with type 1 diabetes. Physiol. Meas., 25: 905-920. PMID: 15382830.

Ismail, T.A., M.M. Soliman and S.A. Ismail, 2013. Adiponectin regulation in type 2 diabetic rats: Effects of insulin, metformin and dexamethasone. Am. J. Pharmacol. Toxicol., 8: 197-208. DOI: 10.3844/ajptsp.2013.197.208

Lehmann, E.D. and T. Deutsch, 1992. A physiological model of glucoseinsulin interaction in type 1 diabetes mellitus. J. Biomed. Eng., 14: 235-242. DOI: $10.1016 / 0141-5425(92) 90058-S$ 
Li, C. and R. Hu, 2007. Simulation study on blood glucose control in diabetics. Proceedings of the $1 \mathrm{st}$ International Conference on Biomedical and Bioinformatics Engineering, Jul. 6-8, IEEE Xplore Press, Wuhan, pp: 1103-1106. DOI: 10.1109/ICBBE.2007.285

Man, C.D. and C. Cobelli, 2006. A system model of oral glucose absorption: Validation on gold standard data. IEEE Trans. Biomed. Eng., 53: 2472-2478. DOI: 10.1109/TBME.2006.883792

Man, C.D., R.A. Rizza and C. Cobelli, 2007. Meal simulation model of the glucose-insulin system. IEEE Trans. Biomed. Eng., 54: 1740-1749. DOI: 10.1109/TBME.2007.893506

Pillonetto, G. Sparacino and C. Cobelli, 2001. Reconstructing insulin secretion rate after a glucose stimulus by an improved stochastic deconvolutionmethod. IEEE Trans. Biomed. Eng., 48: 13521354. DOI: $10.1109 / 10.959332$

Salzsieder, E., G. Albrecht, U. Fischer and E.J. Freys, 1985. Kinetic modeling of the glucoregulatory system to improve insulin therapy. IEEE Trans. Biomed. Eng., 32: 846-855. DOI: 10.1109/TBME.1985.325500
Sorensen, J.T., 1985. A physiologic model of glucose metabolism in man and its use to design and assess improved insulin therapies for diabetes. Ph.D Thesis, Massachusetts Institute of Technology.

Taylor, R., I. Magnusson, D.L. Rothman, G.W. Cline and A. Caumo et al., 1996. Direct assessment of liver glycogen storage by $13 \mathrm{C}$ nuclear magnetic resonance spectroscopy and regulation of glucose homeostasis after a mixed meal in normal subjects. J. Clin. Invest., 97: 126-132. DOI: 10.1172/JCI118379

Thabit, H., 2012. Insulin pump therapy in type 1 diabetesmerging technology with diabetes care. Am. Med. J., 3: 93-99. DOI: 10.3844/amjsp.2012.93.99

Vicini, P., A. Caumo and C. Cobelli, 1997. The hot IVGTT two-compartment minimal model: Indexes of glucose effectiveness and insulin sensitivity. Am. J. Physiol., 273: E1024-E1032. PMID: 9374690

Vicini, P., A. Caumo and C. Cobelli, 1999. Glucose effectiveness and insulin sensitivity from the minimal models: Consequences of undermodeling assessed by Monte Carlo simulation. IEEE Trans. Biomed. Eng., 46: 130-137. DOI: $10.1109 / 10.740875$ 